Care: Jurnal Ilmiah Ilmu Kesehatan Vol .8, No.2, 2020, hal 185-194

Tersedia online di https://jurnal.unitri.ac.id/index.php/care

ISSN 2527-8487 (online)

ISSN 2089-4503 (cetak)

\title{
PERBEDAAN EFEK IMPLEMENTASI BOOKLET DAN MANEKIN PADA PENYULUHAN KEBUTUHAN PERSONAL HIGIENE GENETALIA DI SDN RONOWIJAYAN KABUPATEN PONOROGO JAWA TIMUR
}

\author{
Inna Sholicha Fitriani ${ }^{1)}$, Fetty Rosyadia ${ }^{2)}$ \\ Fakultas Ilmu Kesehatan Universitas Muhammadiyah Ponorogo Jawa Timur \\ E-mail: innasholicha@yahoo.com
}

\begin{abstract}
Adolescence is a period of maturity of human reproductive organs. Candidiasis $25 \%-50 \%$, vaginitis $20 \%-40 \%$ and trichomoniasis 5\% - 15\%. Every teenager must have the right and proper information about reproductive health aspects such as how to maintain the health of reproductive organs, and be able to practice the behavior of maintaining healthy and responsible reproductive organs to avoid diseases that might attack their reproductive organs. This study aims to identify the differences in the effects of the implementation of booklets and mannequins on counseling the personal needs of genetalia bygiene in young women at Ronowijayan Ponorogo Elementary School. This study used an experimental method with a type of randomized experimental study. The research location was the SDN Ronowijayan Siman Ponorogo period of study starting in February December 2018. The study population used was all young women at Ronowijayan Ponorogo Elementary School with a study sample aged 10 untill 12 years at Ronowijayan Ponorogo Elementary School. The results of the data were analyzed using the T test $(a=5 \%)$ with the normality test of the distribution using Shapiro-Wilk. The results of the study were $0.896>0.05$ (95\% confidence), so there was no difference in effect between before treatment and after treatment of the implementation of the booklet with the implementation of manikin. It is necessary to introduce reproductive bealth with a family approach method for young women with the hope that the achievement of reproductive bealth education can be achieved optimally.
\end{abstract}

Keyword : Implementation booklets; mannequins; counseling; personal needs for genetalia bygiene. 


\begin{abstract}
ABSTRAK
Remaja merupakan bagian dari proses perubahan dari periode anak menuju remaja dengan ditandai periode kematangan organ reproduksi. Terdapat kasus pada remaja dengan presentase candidiasis $25 \%-50 \%$, Vaginitis $20 \%-40 \%$ dan trikomoniasis $5 \%-15 \%$. Sebagai seorang remaja perlu memiliki wacana dan pengetahuan yang benar tentang aspek kesehatan khususnya tentang organ reproduksi diantaranya tentang perilaku menjaga organ reproduksi dan mampu mengaplikasikan perilaku yang positif dalam memelihara sehingga dapat terbebas dari masalah dan penyakit pada bagian organ reproduksi. Penelitian ini bertujuan mengidentifikasi perbedaan efek implementasi booklet dan manekin pada penyuluhan kebutuhan personal higiene genetalia pada remaja putri SDN Ronowijayan Ponorogo. Jenis penelitian ini adalah eksperimen random (Randomised Controlled). Lokasi penelitian ini adalah SDN Ronowijayan Siman Ponorogo jangka waktu penelitian mulai Februari 2018- Desember 2018. Populasi penelitian yang digunakan adalah seluruh remaja putri di SDN Ronowijayan Ponorogo. Sampel penelitian ini adalah Pubertas usia $10-12$ th di SDN Ronowijayan Ponorogo. Data hasil dianalisis menggunakan uji $T(\alpha=5 \%)$. Sebelum dilakukan uji $\mathrm{T}$ test, data hasil terlebih dulu diuji normalitas distribusinya menggunakan Shapiro-wilk, Nilai probabilitas atau value uji T paired hasilnya 0,896 > 0,05 ( $95 \%$ kepercayaan) maka tidak ada perbedaan efek antara sebelum perlakuan dan setelah perlakuan dari implementasi booklet dengan implementasi manikin. Sangat perlu pengenalan kesehatan reproduksi dengan metode pendekatan keluarga bagi remaja putri dengan harapan capaian hasil pendidikan kesehatan reproduksi tercapai secara maksimal.
\end{abstract}

Keyword : Implementasi Booklet; Manekin, Penyuluhan Kebutuhan Personal Higiene Genetalia

\section{PENDAHULUAN}

Remaja merupakan bagian dari proses perubahan dari periode anak menuju remaja dengan ditandai periode kematangan organ reproduksi. Perubahan yang terjadi saat ini terkait dengan meningkatnya konsentrasi hormon steroid seks. Pada wanita, sebagian besar perubahan pubertas disebabkan oleh stimulasi estrogen yang berawal dari onset pubertas sentral. Perkembangan yang signifikan terjadi pada organ-organ sistem reproduksi wanita dan mengakibatkan perubahan anatomis yang menjadi ciri kematangan reproduksi
(Colvin CW, 2013). Perempuan di dunia banyak yang mengalami keputihan kurang lebih sejumlah $70 \%$ dengan rentang sekali seumur hidup dan $45 \%$ dengan rentang dua kali atau lebih dalam seumur hidup. Berdasarkan Data Statistik Indonesia tahun 2012 dari 43,3 juta jiwa remaja 15-14 tahun di Indonesia berperilaku tidak sehat. Tindakan personal bygiene yang tidak benar beresiko terhadap tumbuhnya mikroba dan larva serangga sehingga mengakibatkan vagina berbau busuk atau terjadi keputihan, Hal ini dapat menyebabkan timbulnya berbagai penyakit pada organ reproduksi 
(Widyaningrum Nanyk, 2015)

Perawatan organ genital adalah salah satu cara agar alat kelamin selalu sehat dan terhindar dari penyakit yang terjadi pada alat kelamin. Organ genital harus diberi perawatan dengan baik, organ genital merupakan organ yang sangat penting bagi setiap individu. Organ ini sangat rentan terhadap berbagai penyakit sehingga perlu dijaga kesehatannya sehingga memelihara kebersihan area tersebut merupakan hal yang sangat penting. Kebiasaan menjaga kebersihan, termasuk kebersihan organ genital merupakan awal usaha menjaga kesehatan. Perilaku yang tidak sesuai dalam menjaga organ genetalia akan berdampak negative tehadap kesehatan reproduksi, maka dari itu remaja perempuan sangat perlu untuk berperilaku yang sehat guna mencegah munculnya infeksi genitalia dan penyakit organ genetalia yang lainnya. Prosedural menjaga organ reproduksi dimulai dari menjaga personal hygiene diri sendiri, cara membersihkan vagina dengan benar, membersihkan anus dengan benar sehingga terhindar dari masalah seperti keputihan atau infeksi lainnya.

Setiap remaja harus mempunyai bekal informasi yang benar dan tepat mengenai aspek kesehatan reproduksi seperti cara memelihara kesehatan organ reproduksi, serta dapat mempraktekkan perilaku memelihara organ reproduksi yang sehat dan bertanggung jawab agar terhindar dari penyakit-penyakit yang mungkin bisa menyerang organ reproduksinya. Untuk itu remaja putri perlu mengetahui tentang kesehatan reproduksi agar memiliki informasi yang benar mengenai proses reproduksi. Dengan informasi yang benar diharapkan pelajar putri memiliki sikap dan perilaku yang bertanggung jawab tehadap kesehatan reproduksi wanita. Beberapa penyakit-penyakit infeksi pada organ reproduksi wanita. Dalam sebuah proses komunikasi dalam pemberian informasi yang disampaikan oleh Laswell disebutkan bahwa terdapat lima komponen komunikasi agar dapat terjadi sebuah proses komunikasi yaitu komunikator, pesan, media, komunikan serta pengaruh. Media mempunyai peran sebagai sarana untuk menyalurkan pesan atau informasi dari pengirim kepada penerima pesan. Media mempunyai peranan yang sangat penting dalam menentukan keberhasilan proses penyampaian pesan dari komunikator kepada komunikan. Pemilihan media yang tepat akan membantu keberhasilan proses tersebut, sebaliknya penggunaan 
media yang tidak tepat akan menyulitkan komunikan memahami isi pesan dari komunikator. Menurut Notoatmodjo dalam Jayanti (2010), berdasarkan fungsinya media dibagi menjadi 3, yaitu media cetak, seperti booklet, leaflet, flyer, flip chart, rubrik/ tulisan-tulisan poster, foto. Media elektronik, seperti televisi, radio, video compact disc, slide, film strip, serta media papan (bill board). Tujuan penelitian ini adalah Mengidentifikasi Perbedaan Efek Implementasi Booklet Dan Manekin Pada Penyuluhan Kebutuhan Personal Higiene Genetalia Pada Remaja Putri SDN Ronowijayan Ponorogo.

\section{METODE PENELITIAN}

Jenis penelitian ini adalah eksperimen random (Randomised Controlled) den pre dan post test. Lokasi penelitian ini adalah SDN Ronowijayan Siman Ponorogo jangka waktu penelitian mulai Februari 2018- Desember 2018. Populasi penelitian yang digunakan adalah seluruh remaja putri di SDN Ronowijayan Ponorogo . Sampel penelitian ini adalah Pubertas usia $10-12$ th di SDN Ronowijayan Ponorogo sejumlah 34 siswi yang ditentukan dengan cara random sampling, yaitu pengambilan sampel dengan cara di acak yang memenuhi kriteria inklusi. Besar sampel kurang lebih 30 orang dengan alasan menurut Sugiyono, 2013 untuk penelitian eksperimental maka jumlah sampel adalah antara $10-20$ elemen. Alat penelitian yang digunakan adalah booklet, Manekin panggul genetalia, gayung, pembalut wanita, celana dalam, tisu, alas kain, sabun, handuk. Instrumen yang pakai dalam penelitian ini adalah kuisioner. Data hasil dianalisis menggunakan uji $T(\alpha$ $=5 \%$ ). Sebelum dilakukan uji $\mathrm{T}$ test, data hasil terlebih dulu diuji normalitas distribusinya menggunakan Shapiro-wilk, Semua uji statistik yang dipakai menggunakan bantuan software SPSS versi 16.

\section{HASIL}

Tabel 1. Distribusi Frekuensi Menarche Responden

\begin{tabular}{lrrrr}
\hline & $\mathrm{f}$ & $(\%)$ & \multicolumn{1}{c}{$\begin{array}{c}\text { Valid } \\
\text { Persen }\end{array}$} & \multicolumn{1}{c}{$\begin{array}{c}\text { Cumulatif } \\
\text { Persen }\end{array}$} \\
$\begin{array}{l}\text { Pengalaman Menarche } \\
\text { Belum }\end{array}$ & 31 & & 98,98 & 98,98 \\
& & 98,98 & & \\
Sudah & 3 & 1.02 & 1.02 & 1.02 \\
Total & 34 & 100.0 & 100.0 & 100.0 \\
\hline
\end{tabular}


Berdasarkan Table 1 disimpulkan bahwa yang memiliki frekuensi terbanyak adalah belum mengalami menarche dengan jumlah presentase sebanyak 98,98\% atau sebanyak 31 responden.
Berdasarkan Tabel 2 disimpulkan bahwa seluruh responden belum pernah mendapatkan penyuluhan kesehatan reproduksi dengan jumlah presentase sebanyak $100 \%$ atau sebanyak 34 responden.

Tabel 2. Distribusi frekuensi penyuluhan kesehatan reproduksi pada responden

\begin{tabular}{lrrrc}
\hline & Frekuensi & Persen & Valid Persen & $\begin{array}{c}\text { Cumulatif } \\
\text { Persen }\end{array}$ \\
$\begin{array}{l}\text { Mendapatkan Penyuluhan } \\
\begin{array}{l}\text { Belum Pernah Mendapatkan } \\
\text { Penyuluhan }\end{array}\end{array}$ & 34 & 100.0 & 100.0 & 100.0 \\
\hline
\end{tabular}

Dari Tabel 3 ketahui bahwa selisih nilai mean hasil penilaian setelah perlakuan implementasi manekin dengan setelah perlakuan implementasi booklet adalah 0,0588. Dari data di atas dapat di nyatakan bahwa terdapat peningkatan nilai paling banyak adalah menggunakan implementasi manekin. Hasil uji statistik perbedaan antara efek implementasi booklet dan manekin pada kebutuhan personal higiene genetalia di dapatkan

Tabel 3. Nilai mean perbedaan efek implementasi booklet \& manekin pada penyuluhan kebutuhan personal higiene genetalia

\begin{tabular}{|c|c|c|c|c|c|}
\hline \multirow{2}{*}{\multicolumn{2}{|c|}{ Data }} & Sebelum & Sesudah & Sebelum & Sesudah \\
\hline & & Perlakuan & Perlakuan & Perlakuan & Perlakuan \\
\hline \multirow{3}{*}{$\mathrm{N}$} & & Booklet & Booklet & Manekin & Manekin \\
\hline & $\Sigma$ Responden & 17 & 17 & 17 & 17 \\
\hline & Missing & 0 & 0 & 0 & 0 \\
\hline \multicolumn{2}{|c|}{ Mean } & 7.0000 & 17.1765 & 6.7647 & 17.2353 \\
\hline \multicolumn{2}{|c|}{ Std. Deviation } & 1.45774 & 2.12824 & 1.39326 & 2.01648 \\
\hline
\end{tabular}




\section{PEMBAHASAN}

Perubahan fisik pada wanita dimulai pada masa remaja awal, di mana mereka sangat memperhatikan citra tubuh mereka. Berdasarkan hasil penelitian dari pengalaman mengalami menarche yang memiliki frekuensi terbanyak adalah belum mengalami menarche dengan jumlah presentase sebanyak 98,98\% atau sebanyak 31 responden. Rata-rata usia menarche adalah 12,4 tahun Menarche paling sering terjadi pada tingkat kematangan seksual (SMR), atau tahap Tanner, IV. Menarche umumnya dianggap lebih awal jika terjadi sebelum usia 9 tahun dan terlambat jika terjadi pada atau setelah 15 tahun (Langaker, 2018).

Berdasarkan hasil penelitian seluruh responden belum pernah mendapatkan penyuluhan kesehatan reproduksi dengan jumlah presentase sebanyak $100 \%$ atau sebanyak 34 responden. Para remaja putri memiliki prilaku yang kurang baik dalam merawat personal hygiene organ genetalia terutama pada masa haid. Selain itu mereka memiliki perilaku kurang peduli terhadap kesehatan reproduksi. Berdasarkan penelitian Wulandari ( 2012 ) diketahui bahwasanya remaja putri sebagian besar memiliki pengetahuan yang cukup sebanyak $63 \%$ tentang prosedural perawatan genetalia bagian eksternal. Selanjutnya mereka memiliki perilaku yang cukup dalam upaya menjaga kebersihan organ genetalia bagian eksternal. Sebanyak $48 \%$. Hal ini terjadi karena dipengaruhi factor pendidikan yang masih rendah dan usia yang masih muda dan labil. Selain itu informasi terkait kesehatan reproduksi banyak yang beranggapan sangat tabu bila disampaikan kepada orang awam. Pendidikan kesehatan reproduksi seharusnya diberikan sejak dini hal ini karena memiliki tujuan agar menjadi bekal bagi para remaja yang mulai menginjak masa peralihan dan memiliki perubahan yang signifikans terkait organ reproduksi (Pythagoras, 2017).

Pada remaja putri dalam upaya mendapatkan pengetahuan dalam proses pendidikan terdapat faktor-faktor yang mempengaruhi dalam belajar. Faktor intern yang mempengaruhi adalah lingkungan, budaya. Kemudian factor ektern dipengaruhi oleh kesehatan fisik \& psikis. Selanjutnya tema materi dan bobot dari materi itu sendiri juga dapat mempengaruhi minat remaja dalam proses belajar sehingga dapat 
mempengaruhi hasil akhir dari proses pendidikan (Suiraoka P, 2012).

Salah satu langkah yang tepat dalam upaya pemberian informasi pada remaja dengan menggunakan metode pendidikan kesehatan, yang merupakan bagian dari hak reproduksi bagi remaja dalam upaya peningkatan pengetahuan dan berperilaku yang dapat dipertanggunjawabkan dan mampu mengubah perilaku remaja. Pesan informasi kesehatan reproduksi diterima oleh remaja beberapa kali dari media, organisasi keagamaan, sekolah, dan rekan-rekan keluarga, orang tua / pengasuh, dan mitra, meskipun kualitas informasinya bervariasi ( Cora C, 2016 ).

Salah satu faktor yang mempengaruhi tingkat keberhasilan dalam pemberian pendidikan kesehatan adalah adanya media yang tepat. Menurut Permatasari (2004) menjelaskan bahwa booklet merupakan media komunikasi yang bersifat promosi, anjuran, laranganlarangan kepada khalayak massa, dan berbentuk cetakan, yang memiliki tujuan agar masyarakat yang sebagai objek dapat memahami pesan yang disampaikan melalui media ini. Booklet merupakan salah satu media yang tercetak dan memiliki keunggulan dapat dipelajari lebih mudah dengan memiliki desain layaknya buku, informasinya lebih banyak dibandingkan poster namun memiliki bobot desain lebih variatif dan menarik (Gemilang, 2016). Sedangkan manikin merupakan tiruan tubuh manusia yang terbuat dari bahan silicon atau karet yang dapat digunakan sebagai media peraga.

Dari hasil penelitian diketahui selisih sebelum dan sesudah perlakuan pada kelompok booklet tidak sebaik pada kelompok manekin. Hal ini menunjukkan bahwa skor perubahan perilaku remaja putri tentang kebutuhan personal hygiene dengan media manekin lebih baik daripada dengan media booklet. Materi yang disajikan dengan media booklet hanya mengandalkan indera penglihatan saja, sehingga kurang dapat diserap dan dipahami secara optimal oleh remaja putri, sedangkan menggunakan media manikin selain mengandalkan media ceramah dari penyuluh, mereka juga melihat bagaimana cara memperagakan teknik memenuhi kebutuhan personal hygiene pada genetalia sehingga bisa mengubah mindset pada remaja putri.

Diantara kedua media tedapat perbedaan yang memungkinkan untuk mempengaruhi hasil dari peningkatan 
prilaku positif dari kedua kelompok. Pada kedua media terdapat isi materi yang sama, dan yang membedakannya adalah dalam hal penyajian materinya. Penyajian materi pada media booklet lebih singkat, padat, dan detail jika dibandingkan dengan media manekin, Dilihat dari ketertarikan media, manikin terdapat kelebihan materi langsung bisa diterapkan oleh remaja putri, hal ini juga berpengaruh terhadap ketertarikan anak untuk ingin mencobanya, dengan mencoba remaja putri lebih mudah memahami dan menerapkan sehingga lebih kuat mempengaruhi perilaku remaja putri untuk memenuhi kebutuhan personal hygiene genetalia secara positif.

Dari hasil uji $\mathrm{T}$ paired test di ketahui hasilnya adalah nilai probabilitas atau value uji T paired hasilnya 0,896>0,05 ( $95 \%$ kepercayaan) maka tidak ada perbedaan efek antara sebelum perlakuan dan setelah perlakuan dari implementasi booklet dengan implementasi manekin. bahwa kedua media tersebut yaitu booklet dan manekin sama- sama efektif dapat meningkatkan perilaku positif terhadap pemenuhan kebutuhan personal hygiene genetalia. Hal ini dapat terjadi efek dari setelah pemberian pendidikan kesehatan, antara media booklet maupun manikin ada langkah atau metode memberikan pertanyaan dan dapat dijawab sehingga mampu mempengaruhi dalam pengisian checklist kuesioner, hal lain yang dapat mempengaruhi adalah pengaruh lingkungan serta kondisi saat responden duduk atau mampu berinteraksi dengan orang lain yang dapat menurunkan tingkat konsentrasi serta tidak kondusifnya pengisian checklist kuesioner (Irwan, 2017).

Machfoedz (2005) menyebutkan bahwa pendidikan kesehatan adalah sebagai hubungan timbal balik antara dua orang individu (penyuluh dan klien) untuk mencapai pengertian tentang diri sendiri dalam hubungan dengan masalahmasalah yang dihadapi pada waktu yang akan datang. Samsudin menyebutkan fungsi dari pendidikan kesehatan adalah sebagai penghubung yang menjabarkan proses penyampaian ilmu dan teknologi dari sumbernya kepada masyarakat yang membutuhkanya Penyuluhan tidak dapat lepas dari media karena melalui media pesan disampaikan dengan mudah untuk dipahami. Media promosi kesehatan dapat dikelompokan menjadi media cetak,media elektronik dan media luar ruangan (Notoatmodjo S, 2010). 
Menurut Notoatmodjo (2010) upaya intervensi terhadap faktor perilaku dapat dilakukan melalui dua pendekatan, yaitu pendidikan atau paksaan/tekanan, dan pendekatan pendidikan adalah yang paling tepat sebagai upaya untuk memberikan intervensi terhadap perlikau remaja putri dalam menjaga personal hygiene genetalia. Satu hal yang merupakan point penting dalam pendidikan kesehatan adalah pemilihan dan penggunaan media yang digunakan Dalam rangka pemberian pendidikan kesehatan sebgai upaya promotif pada remaj tingkat sekolah sebaiknya menggunakan kata atau tata bahasa dan format materi yang disesuaikan dengan kebutuhan siswa remaja. Pertanyaan yang disusun dalam checklist kuesioner juga harus di standarkan dengan tingkat intelektual siswa remaja sehingga sesuai dengan sasaran yang dikehendaki (Waldani D, Rasyid R, 2018).

\section{KESIMPULAN}

Dari hasil penelitian karakteristik reponden di peroleh data usia responden yang memiliki frekuensi terbanyak adalah usia 11 tahun, kemudian responden paling banyak adalah belum mengalami menarche. Seluruh responden belum pernah mendapatkan penyuluhan kesehatan reproduksi. Hasil uji statistik tidak ada perbedaan efek antara sebelum dan setelah perlakuan dari implementasi booklet dengan implementasi manekin.

\section{UCAPAN TERIMAKASIH}

Ucapan terima kasih diberikan kepada :

1. LPPM Universitas Muhammadiyah Ponorogo sebagai lembaga pemberi dana penelitian intern tahun anggaran 2018

2. Kepala Sekolah SDN Ronowijayan Ponorogo sebagai lahan penelitian yang telah memberikan ijn penelitian

3. Seluruh siswi SDN Ronowijayan Ponorogo sebagai responden yang telah bersedia menjadi subyek penelitian

4. Seluruh pihak yang telah terlibat dalam kegiatan penelitian ini

\section{REFERENSI}

Colvin CW, H. A. (2013). Anatomy of Female Puberty: The Clinical Relevance of Developmental Changes in the Reproductive System. Clin Anat, Jan;26(1), 115129. https://doi.org/doi: 10.1002/ca.22164.

Gemilang, R. E. C. (2016). Pengembangan Booklet Sebagai Media Layanan Informasi Untuk Pemahaman Gaya Hidup Hedonisme Siswa Kelas XI di SMAN 3 Sidoarjo. Jurnal Bk Unesa. Irwan. (2017). Etika dan Perilaku 
Kesehatan. CV. Absolute Media.

Langaker, L. A. H. G. M. D. (2018).

Physiology, Menarche. NCBI.

www.ncbi.nlm.nih.gov/books/NB

K470216/

Notoatmodjo S. (2010). Promosi Kesehatan.

Rineka Cipta.

Pythagoras, K. C. (2017). Personal

Hygiene Remaja Putri Ketika

Menstruasi. Jurnal Promkes, Vol 5 No

1.

Suiraoka P, S. D. (2012). Media Pendidikan

Kesehatan (1st ed.). graha ilmu.

Waldani D, Rasyid R, Z. A. (2018).

Pengaruh Penyuluhan Gizi

Terhadap Perubahan Perilaku

Kebiasaan Sarapan Pagi Murid SD

Negeri 05 Solok Selatan Tahun

2016. Jurnal Kesehatan Andalas, 7(2).

Widyaningrum Nanyk. (2015). Pengaruh

Penyuluhan Tentang Personal

Hygiene Terhadap Perilaku Personal

Hygiene Saat Menstruasi di MTSN

Negeri Gubuk Rubuh Gunung

Kidul Yogyakarta.

Digilib.Unisayogya.Ac.Iddigilib.Unisayog

ya.Ac.Id. 